Research Article

\title{
Seismic Damage Rapid Assessment of Road Networks considering Individual Road Damage State and Reliability of Road Networks in Emergency Conditions
}

\author{
Jinlong Liu $\mathbb{D}^{1,2}$ Hanxi Jia, ${ }^{1}$ Junqi Lin, ${ }^{1}$ and Heng $\mathrm{Hu}^{1}$ \\ ${ }^{1}$ Key Laboratory of Earthquake Engineering and Engineering Vibration, Institute of Engineering Mechanics, \\ China Earthquake Administration, Harbin 150080, China \\ ${ }^{2}$ Heilongjiang Provincial Key Laboratory of Underground Engineering Technology, Harbin 150086, China
}

Correspondence should be addressed to Jinlong Liu; liuliu_jinlong@163.com

Received 23 February 2020; Revised 28 June 2020; Accepted 21 July 2020; Published 6 August 2020

Academic Editor: Xue Zhang

Copyright (c) 2020 Jinlong Liu et al. This is an open access article distributed under the Creative Commons Attribution License, which permits unrestricted use, distribution, and reproduction in any medium, provided the original work is properly cited.

Road networks are one of the vital components of a transportation system that influence the traffic capacity and disaster losses after the earthquakes. The road network reliability is crucial for the postearthquake emergency decision-making. In this study, a method is proposed to assess the seismic damage of road networks considering individual road damage state and reliability of road networks in emergency conditions. First, we assess the importance of the factors that affect seismic road damage using the AdaBoost algorithm. In addition, artificial neural networks are used to evaluate the damage state of an individual road based on the factors that are selected with higher importance. Then, the improved estimation for the reliability of road networks is adopted to assess the damage of road networks. Last, the method is demonstrated using the road networks in Karamay, China.

\section{Introduction}

Lifeline systems refer to the infrastructure networks, including transportation, communication, water supply, drainage, power supply, gas supply, and oil transportation, which have a major impact on social life and production [1]. The road networks are one of the critical components of the transportation system that transmit information in the lifeline systems. They are also the life passage for seismic relief after the earthquake. Rapidly and accurately assessing the damage state of the road networks after the earthquake can provide reference information for the deployment of emergency rescue works and rationally distribute the manpower and material resources for disaster relief. A timely rescue can reduce the casualties and property losses in the disaster areas.

In recent years, the seismic damage evaluations of the transportation networks have been widely investigated by some studies. In these past studies, most of them regard bridge failure as the main factor affecting the capacity of the road network, while ignoring the impact of road failure on the overall performance of the road network [2]. Kiremidjian et al. proposed an assessment model of the transportation networks based on the loss evaluation of the bridges [3]. Guo et al. considered the roads as the main components of the transportation systems in their method, which were developed according to postdisaster traffic demand [4]. However, the focus of the research proposed by Guo et al. remained the bridges. Some researchers have focused studies on the road networks. The method proposed by Cheng et al. was based on the road network capacity (RNC) model and combined travel demand model, which was mainly calculated by the original-destination (OD) matrix [5]. It is only required to solve the shortest path traffic reliability between all OD sets and OD sets of the road networks [6]. The expected value of the traffic probability of all the shortest paths [7] is the connectivity reliability of the road network, which can be used to evaluate the overall operation of the road networks after the earthquake. The method can reflect the structure and evaluate the traffic 
capacity of the road network. However, as road network vertices increase, the calculation of the number of $\mathrm{OD}$ sets will increase exponentially [8], which will greatly increase the workload of assessment. Hence, a faster calculation method is needed to assess the road capacity after the earthquake.

Furthermore, the damage assessments of the individual road were ignored in most previous studies [9-11]. Pitilakis et al. investigated the dynamic transportation performance directly based on the whole road networks [10]. Some studies are used to evaluate the road seismic damage based on the linear regression model [12]. The causes of the road damages are very complicated, and they are not only influenced by the earthquakes. However, the linear models are still flawed in solving the problem of very complicated internal mechanism, and they often need some assumptions. In recent years, the rises of machine learning algorithms have greatly advanced the development of the prediction problems [13]. For example, the ANN model was used to assess the bridge damage severity quantification [14] and buildings' damage seismic state [15]. The ANN model also has almost no application in the road network seismic damage assessment. Before using the ANN model to predict, the features should be screened first rather than by empirically selecting the influencing factors [12]. One of the best ways to choose the factors that influence road damage is to assess the importance of them [16]. The method of ensemble learning algorithms has been proved to have a good performance in the analysis of feature importance [16-18]. There are many algorithms in the ensemble learning models, such as the most commonly used random forest algorithm [19] and adaptive boosting algorithm (AdaBoost) [20]. However, ensemble learning models have not been used to assess the importance of different influencing factors of seismic road damage.

This paper shows a method for the seismic damage assessment of road networks considering the damage state of an individual road and reliability of road networks. The first part of this method consists of two models: (1) the assessment of factor importance applying the AdaBoost algorithms [20] and (2) the estimation of the damage state of an individual road using the ANN model based on the results of the AdaBoost model. The second part is to evaluate the reliability of road networks considering the capacity of road networks (RNC) and pass probability based on the results of the ANN model. Finally, we use a case study to verify the applicability of the method proposed in this study, and it is proved that the method has a good performance on the problem of the seismic damage assessment of road networks.

\section{Data}

Because the data of the road are less than the bridge in an earthquake, some studies have to make some assumptions so as to verify the efficiency of their method. The data used in this article are derived from actual seismic damage and do not contain any assumptions. The road damage data were collected by the government and some institutions (Sichuan Highway Planning, Survey and Design Institute, China Highway Planning and Design Institute, and Shanxi
Highway Planning Survey and Design Institute). They were all derived from the 2008 Ms 8.0 Wenchuan earthquake in China (Table 1). In Table 1, the seismic fortification intensity and soil type refer to the "Chinese Specification of Seismic Design for Highway Engineering" (JTG B02-2013) [21], and the practical intensity refers to the Chinese seismic intensity scale (GBT 17742-2008) [22].

There were five national highways (G108, G212, G213, G317, and G318) and eleven provincial highways (S101, S105, S106, S202, S205, S210, S211, S301, S302, S303, and S306) in the disaster-stricken areas of Sichuan province damaged to varying degrees. National road G213, provincial road S302, and provincial road S303 crossing the area of earthquake intensity VIII were seriously damaged, and the total damage of rural roads was about 24,103 kilometers. There were two national highways (G212 and G316) and nine provincial highways (S205, S206, S208, S219, S306, S307, S313, X482, and X484) in Gansu province which were damaged to varying degrees, and the total damage was about 5518 kilometers including rural roads. There were only one national highway (G108) and two provincial highways (S210 and S309) in Shanxi province which were damaged to varying degrees, and the total damage was about 1,791 kilometers including rural roads. The above roads were divided into 63 links based on the damage and mileage. Figure 1 demonstrates some typical damages of the road in the Wenchuan earthquake, which were divided into some road segments and had the individual number [24].

\section{Assessment of Seismic Road Damage}

3.1. Select Factors. There are many factors affecting road seismic damage, but not every factor is critical. In the rapid assessment of road damage, the most important factors should be selected for evaluation, which can save time in obtaining data and running procedures.

The road is mainly composed of subgrade and pavement, retaining structure, and slope. The road damage is divided into three types based on the failure parts: subgrade damage, supporting structure damage, and slope damage. The seismic damage data show that the three seismic types are not independent. For example, the retaining structure or subgrade will be destroyed when the slope collapses. The following is a detailed description of the selection factors (Figure 2) (Tables 2 and 3):

(1) Different road grades have different importance in seismic design. According to the Chinese Design Code of Highway Subgrades (JTG D30-2015) [25], the road can be divided into 4 grades. For each grade, the road has different materials and construction methods, and so, the earthquake resistance ability of each grade road is different.

(2) Subgrade-related factors included the subgrade type and height difference of the subgrade [26]. The type of subgrade was classified according to the form of excavation and filling. The subgrade height difference is the difference between the design elevation of the subgrade centerline and the original ground 
TABLE 1: The damage roads of the Wenchuan earthquake with some characteristics; the number consists of the road name and the mileage number.

\begin{tabular}{|c|c|c|c|c|c|c|c|}
\hline Number & $\begin{array}{c}\text { Height } \\
\text { difference }(\mathrm{m})\end{array}$ & $\begin{array}{c}\text { Road } \\
\text { grades }\end{array}$ & $\begin{array}{l}\text { Supporting and } \\
\text { retaining type }\end{array}$ & $\begin{array}{c}\text { Seismic fortification } \\
\text { intensity }\end{array}$ & $\begin{array}{c}\text { Practical intensity } \\
\text { (degree) }\end{array}$ & $\begin{array}{c}\text { Slope } \\
\text { height }(\mathrm{m})\end{array}$ & $\begin{array}{c}\text { Soil type of } \\
\text { the site }\end{array}$ \\
\hline $\begin{array}{l}\text { G213: } \\
\text { K1020 + } 960\end{array}$ & 10.4 & 3 & Gravity-type grouted & VII & XI & 13.6 & II \\
\hline $\begin{array}{l}\text { G213: } \\
\text { K1018 + } 600\end{array}$ & 1.2 & 3 & Gravity-type grouted & VII & $\mathrm{XI}$ & 40.0 & I \\
\hline $\begin{array}{l}\text { G213: } \\
\text { K1022 + } 900\end{array}$ & 15.6 & 3 & $\begin{array}{c}\text { Reinforced retaining } \\
\text { wall }\end{array}$ & VII & XI & 0 & I \\
\hline $\begin{array}{l}\text { G213: } \\
\text { K1029 + } 850\end{array}$ & 3.1 & 3 & Gravity-type grouted & VII & $\mathrm{X}$ & 33.0 & I \\
\hline $\begin{array}{l}\text { G213: } \\
\text { K1008 + } 900\end{array}$ & 3.0 & 3 & Gravity-type grouted & VII & XI & 20.0 & I \\
\hline $\begin{array}{l}\text { G213: } \\
\text { K1014+ } 175\end{array}$ & 6.0 & 3 & Gravity-type grouted & VII & XI & 0 & I \\
\hline $\begin{array}{l}\text { G213: } \\
\text { K1008 + } 400\end{array}$ & 2.0 & 3 & Cutting slope & VII & $\mathrm{XI}$ & 50.0 & III \\
\hline $\begin{array}{l}\text { G213: } \\
\text { K1008 + } 580\end{array}$ & 9.9 & 3 & $\begin{array}{l}\text { Gravity-type } \\
\text { concrete }\end{array}$ & VII & XI & 50.0 & III \\
\hline $\begin{array}{l}\text { G213: } \\
\text { K1012+ } 400\end{array}$ & 13.6 & 3 & $\begin{array}{l}\text { Gravity-type } \\
\text { concrete }\end{array}$ & VII & XI & 15.5 & III \\
\hline $\begin{array}{l}\text { G213: } \\
\text { K1029+ } 700\end{array}$ & 6.2 & 3 & $\begin{array}{l}\text { Gravity-type } \\
\text { concrete }\end{array}$ & VII & $\mathrm{X}$ & 50.0 & III \\
\hline $\begin{array}{l}\text { G213: } \\
\text { K1023 + } 700\end{array}$ & 2.2 & 3 & Prestressed cable & VII & XI & 19.0 & III \\
\hline $\begin{array}{l}\text { G213: } \\
\text { K1009 + } 080\end{array}$ & 7.1 & 3 & Cutting slope & VII & XI & 0 & III \\
\hline $\begin{array}{l}\text { G213: } \\
\text { K1008 + } 980\end{array}$ & 4.0 & 3 & $\begin{array}{l}\text { Gravity-type } \\
\text { concrete }\end{array}$ & VII & XI & 0 & III \\
\hline $\begin{array}{l}\text { G213: } \\
\text { K916+ } 508\end{array}$ & 3.6 & 3 & Cutting slope & VII & IX & 7.0 & III \\
\hline $\begin{array}{l}\text { G213: } \\
\mathrm{K} 37+350\end{array}$ & 1.8 & 2 & Gravity-type grouted & VII & $\mathrm{X}$ & 294.0 & II \\
\hline $\begin{array}{l}\text { G213: } \\
\mathrm{K} 38+500\end{array}$ & 1.0 & 2 & Gravity-type grouted & VII & $\mathrm{X}$ & 326.3 & II \\
\hline $\begin{array}{l}\text { G213: } \\
\mathrm{K} 40+100\end{array}$ & 3.6 & 2 & Gravity-type grouted & VII & $\mathrm{X}$ & 121.2 & I \\
\hline $\begin{array}{l}\text { G213: } \\
\mathrm{K} 42+400\end{array}$ & 4.4 & 2 & Facing wall & VII & $\mathrm{X}$ & 175.5 & II \\
\hline $\begin{array}{l}\text { G213: } \\
\mathrm{K} 26+800\end{array}$ & 1.5 & 2 & Cutting slope & VII & XI & 24.3 & I \\
\hline $\begin{array}{l}\text { G213: } \\
\text { K73 + } 000\end{array}$ & 2.0 & 2 & Cutting slope & VII & IX & 175.9 & I \\
\hline $\begin{array}{l}\text { G213: } \\
\mathrm{K} 29+950\end{array}$ & 1.0 & 2 & Facing wall & VII & XI & 19.7 & I \\
\hline $\begin{array}{l}\text { G213: } \\
\mathrm{K} 34+140\end{array}$ & 1.5 & 2 & Cutting slope & VII & XI & 122.7 & III \\
\hline $\begin{array}{l}\text { G213: } \\
\mathrm{K} 35+600\end{array}$ & 3.9 & 2 & Cutting slope & VII & XI & 100.0 & III \\
\hline $\begin{array}{l}\text { G213: } \\
\mathrm{K} 50+200\end{array}$ & 3.0 & 2 & Cutting slope & VII & $\mathrm{X}$ & 480.1 & III \\
\hline $\begin{array}{l}\text { G213: } \\
\text { K58 + } 160\end{array}$ & 3.4 & 2 & Gravity-type grouted & VII & $\mathrm{X}$ & 15.0 & III \\
\hline G213 & 1.5 & 3 & Gravity-type grouted & VII & IX & 7.1 & III \\
\hline G213 & 1.7 & 3 & Gravity-type grouted & VII & IX & 92.1 & II \\
\hline G213 & 4.0 & 3 & Gravity-type grouted & VII & IX & 27.0 & II \\
\hline G213 & 3.4 & 3 & Cutting slope & VII & IX & 93.4 & III \\
\hline G213 & 2.3 & 3 & Facing wall & VII & IX & 71.0 & III \\
\hline G213 & 1.5 & 3 & Gravity-type grouted & VII & IX & 0 & II \\
\hline G213 & 1 & 3 & Gravity-type grouted & VII & IX & 10.0 & II \\
\hline G213 & 1.2 & 3 & Cutting slope & VII & IX & 0 & II \\
\hline
\end{tabular}


TABLE 1: Continued.

\begin{tabular}{|c|c|c|c|c|c|c|c|}
\hline Number & $\begin{array}{c}\text { Height } \\
\text { difference }(\mathrm{m})\end{array}$ & $\begin{array}{c}\text { Road } \\
\text { grades }\end{array}$ & $\begin{array}{c}\text { Supporting and } \\
\text { retaining type }\end{array}$ & $\begin{array}{c}\text { Seismic fortification } \\
\text { intensity }\end{array}$ & $\begin{array}{c}\text { Practical intensity } \\
\text { (degree) }\end{array}$ & $\begin{array}{c}\text { Slope } \\
\text { height }(\mathrm{m}) \\
\end{array}$ & $\begin{array}{c}\text { Soil type of } \\
\text { the site }\end{array}$ \\
\hline $\begin{array}{l}\text { S303: } \\
\mathrm{K} 10+341\end{array}$ & 1.8 & 2 & Gravity-type grouted & VII & $\mathrm{X}$ & 5.0 & III \\
\hline $\begin{array}{l}\text { S303: } \\
\text { K28 + } 941\end{array}$ & 0.5 & 2 & Gravity-type grouted & VII & $\mathrm{X}$ & 50.0 & II \\
\hline $\begin{array}{l}\text { S303: } \\
\mathrm{K} 40+500\end{array}$ & 0.5 & 2 & Gravity-type grouted & VII & IX & 27.4 & III \\
\hline $\begin{array}{l}\text { S303: } \\
\text { K16+441 }\end{array}$ & 2.6 & 2 & Cutting slope & VII & $\mathrm{X}$ & 237.5 & II \\
\hline S303: K31 + 841 & 1.0 & 2 & Cutting slope & VII & IX & 28.7 & I \\
\hline $\begin{array}{l}\text { S303: } \\
\text { K36 + 600 }\end{array}$ & 1.0 & 2 & Cutting slope & VII & IX & 100.0 & III \\
\hline $\begin{array}{l}\text { S303: } \\
K 43+200\end{array}$ & 1.0 & 2 & Cutting slope & VII & IX & 30.0 & II \\
\hline $\begin{array}{l}\text { S303: } \\
\text { K26+900 }\end{array}$ & 3.1 & 2 & Gravity-type grouted & VII & IX & 25.0 & III \\
\hline S302 & 2.0 & 2 & Cutting slope & VII & IX & 27.0 & III \\
\hline $\begin{array}{l}\text { S302: } \\
\text { K732+ } 560\end{array}$ & 1.5 & 2 & Gravity-type grouted & VII & $\mathrm{X}$ & 7.4 & III \\
\hline S302 & 2.5 & 2 & Facing wall & VII & $\mathrm{X}$ & 47.5 & I \\
\hline S105 & 2.2 & 3 & Gravity-type grouted & VII & $\mathrm{XI}$ & 2.8 & I \\
\hline S105 & 3.1 & 3 & Gravity-type grouted & VII & $\mathrm{XI}$ & 25.3 & III \\
\hline S105 & 3.5 & 3 & Facing wall & VII & $\mathrm{XI}$ & 36.7 & I \\
\hline $\begin{array}{l}\text { S105: } \\
\text { K167 + 460 }\end{array}$ & 5.9 & 3 & Cutting slope & VII & $\mathrm{XI}$ & 8.4 & III \\
\hline $\begin{array}{l}\text { S105: } \\
\text { K168+900 }\end{array}$ & 7.4 & 3 & Cutting slope & VII & $\mathrm{XI}$ & 9.0 & III \\
\hline XU09 & 2.3 & 4 & $\begin{array}{c}\text { Gravity-type } \\
\text { concrete }\end{array}$ & VI & $\mathrm{X}$ & 44.3 & II \\
\hline S210 & 1.3 & 3 & Gravity-type grouted & VII & VII & 324.4 & I \\
\hline S210 & 3.7 & 3 & Cutting slope & VII & VII & 63.6 & II \\
\hline S210 & 2.3 & 3 & Cutting slope & VII & VII & 24.4 & III \\
\hline G212 & 4.2 & 3 & Gravity-type grouted & VII & VIII & 34.3 & II \\
\hline G213 & 1.0 & 2 & Gravity-type grouted & VII & VIII & 20.3 & I \\
\hline S303 & 3.8 & 4 & Cutting slope & VII & VII & 194.3 & III \\
\hline S303 & 4.2 & 4 & Gravity-type grouted & VII & VIII & 35.0 & III \\
\hline G317 & 1.5 & 3 & Cutting slope & VII & VII & 173.3 & II \\
\hline G317 & 2.5 & 2 & Gravity-type grouted & VII & VI & 2.5 & II \\
\hline G317 & 2.4 & 2 & Gravity-type grouted & VII & VI & 5.0 & I \\
\hline G317 & 0.5 & 2 & No & VII & VI & 0 & III \\
\hline G317 & 6.0 & 2 & Gravity-type grouted & VII & VI & 0 & III \\
\hline
\end{tabular}

elevation, which was used to describe the stability of the subgrade in the earthquake. The diagrammatic drawing of the subgrade type is shown in Figure 2.

(3) The retaining structures are used to support and stabilize the subgrade filling or slope to prevent soil slipping and thus to maintain soil stability [27]. The retaining structure can be divided into gravity retaining wall and flexible retaining wall. Gravity retaining wall can be divided into three types according to the construction method: dry masonry, wet masonry, and concrete. The seismic damage data show that the dry masonry retaining wall is more prone to serious damage, and its actual seismic capacity is obviously weaker than that of wet and concrete, so the dry masonry retaining wall and the nonretaining wall are combined into one category. The reinforced retaining wall, antislide pile, and anchor cable structure with good seismic performance are classified as advantageous retaining, so the retaining types are divided into four categories: nonretaining, wet masonry gravity, concrete gravity, and advantageous retaining.

(4) The site soil has a great influence on the bearing capacity of the foundation [28]. In the Wenchuan earthquake, a large number of shoulder walls were inclined and deformed due to insufficient bearing capacity of the foundation. According to the Specification of Seismic Design for Highway Engineering (JTG B02-2013) [21], the engineering site is divided into four categories, as shown in Table 2.

(5) Slope-related factors select slope angle, height, and protective measures. As the slope height and slope increase, the number of earthquake damage 

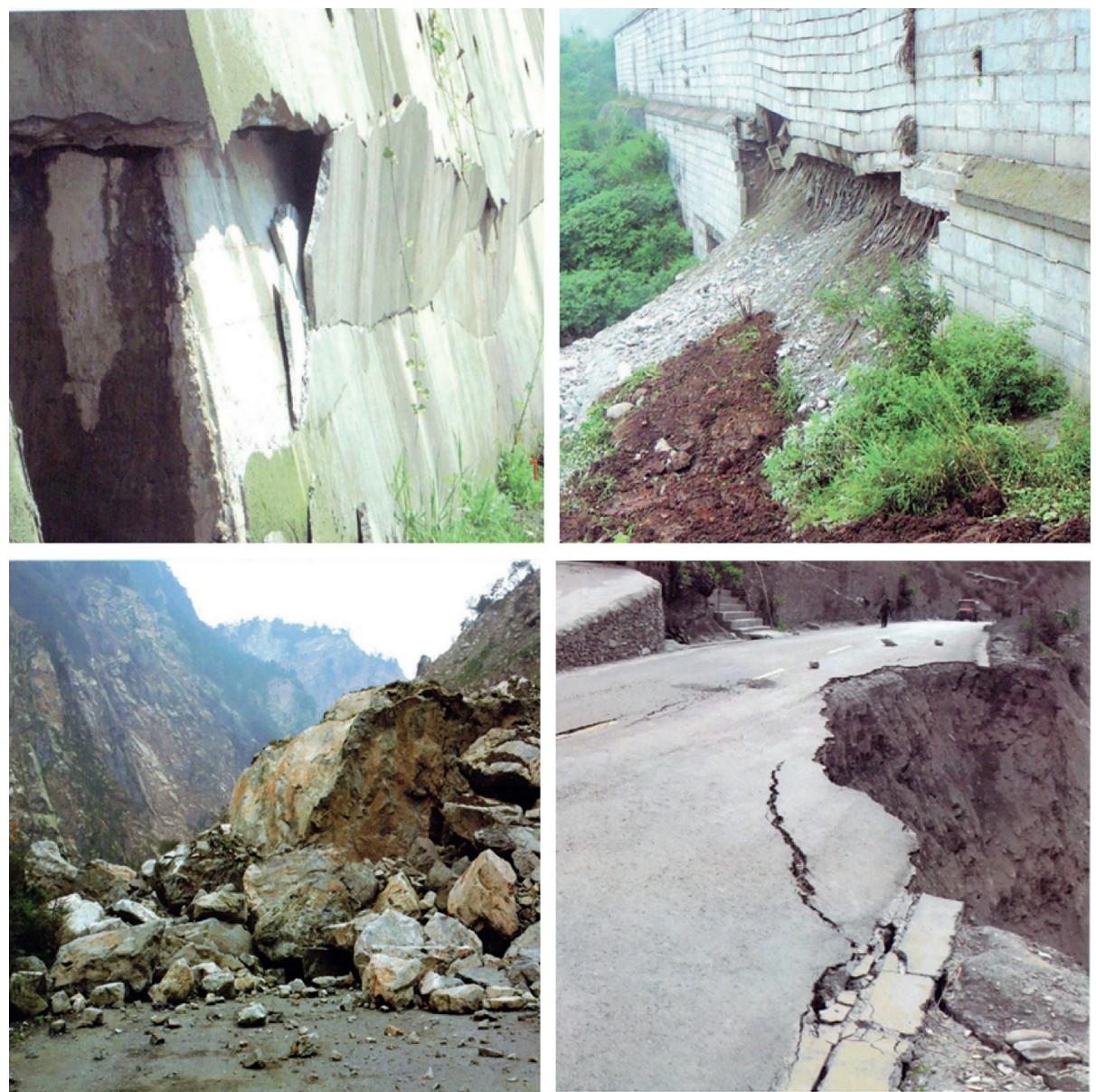

FIGURE 1: The typical damage of the road in the Wenchuan earthquake, including the retaining wall being cut, the wall body being inclined outward, the subgrade being buried by the rock, and the subgrade partially collapsed [23].

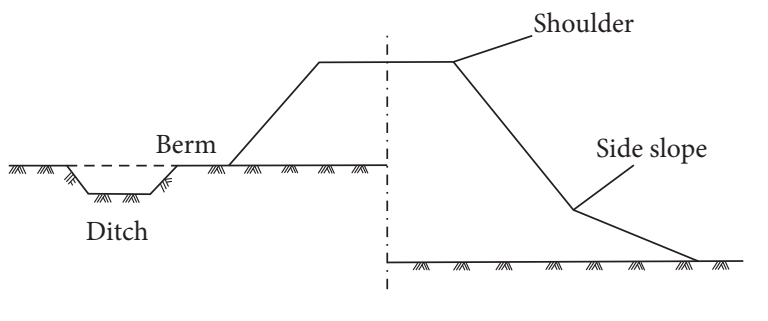

(a)

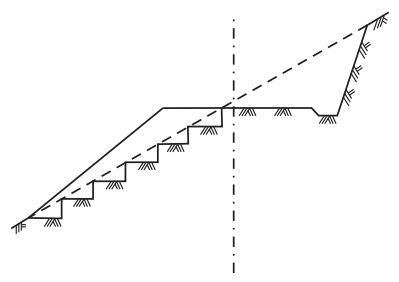

(c)

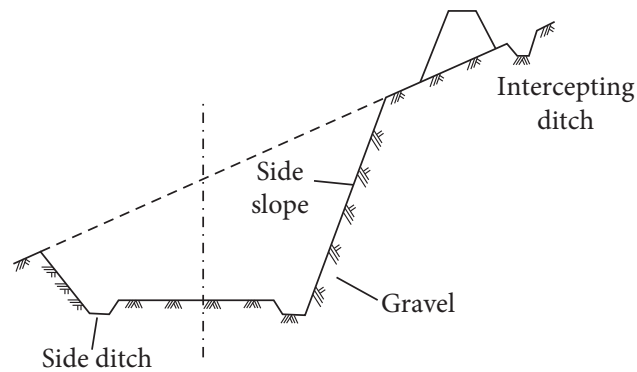

(b)

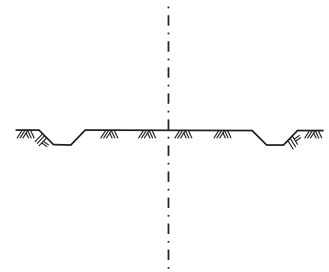

(d)

Figure 2: Diagrammatic drawing of the subgrade type. (a) Embankment. (b) Cutting. (c) Half-filled and half-dug. (d) No digging and no filling. 
TABLE 2: Classification of engineering sites.

\begin{tabular}{|c|c|c|c|c|}
\hline \multirow{2}{*}{ Mean shear wave velocity $(\mathrm{m} / \mathrm{s})$} & \multicolumn{4}{|c|}{ Site category } \\
\hline & I & II & III & IV \\
\hline$v_{s e}>500$ & 0 & - & - & - \\
\hline $500 \geq v_{s e}>250$ & $<5$ & $\geq 5$ & - & - \\
\hline $250 \geq v_{s e}>140$ & $<3$ & $\geq 3, \leq 50$ & $>50$ & - \\
\hline$v_{s e} \leq 140$ & $<3$ & $\geq 3, \leq 15$ & $>15, \leq 80$ & $>80$ \\
\hline
\end{tabular}

TABLE 3: Classification of slope protection types.

\begin{tabular}{lc}
\hline Classification & Slope protection type \\
\hline Level I & No protection, wall protection, plant protection, spraying (no net) \\
Level II & Net hanging, shotcrete, active and passive protection net \\
Level III & Frame beam, prestressed anchor (cable) protection, composite measures \\
\hline
\end{tabular}

increases simultaneously. The higher the slope is, the more obvious the acceleration amplification effect is under the action of the earthquake, which is easy to produce earthquake damage such as rock projectile. Similarly, the steeper the slope is, the worse the stability will be. In the Wenchuan earthquake, the slope damage mainly concentrates on the slope between $35^{\circ}$ and $65^{\circ}$. In addition, the characteristics of seismic damage show that the seismic damage of the slope mainly occurs on the soil slope without protection, while the failure of the slope with the combination of the frame, anchor bolt, and multimeasures is less. This indicates that appropriate protective measures can effectively reduce the degree and quantity of damage to the slope. According to the slope protection method, slope protection can be divided into three categories, as shown in Table 3; from type I to type III, the seismic protection capability of the slope is gradually enhanced.

(6) The seismic intensity describes the intensity of the earthquake. The damage data of the Wenchuan earthquake also show that the amount and extent of damage increase with the increase of intensity, which is consistent with our understanding. The seismic fortification level is an important factor of road's seismic resistance ability. In the engineering design stage, the seismic resistance of the road will be guaranteed according to the corresponding specifications [21]. Therefore, the fortification intensity can be taken as one of the evaluation indexes.

Above all, we estimated the importance of ten factors as follows: highway classification, subgrade type, supporting and retaining type, soil type of the site, slope height, slope angle, protective measure, height difference of subgrade, seismic fortification intensity, and practical intensity (Table 4).

\subsection{Assessment of the Factor Importance Applying the Ada-} Boost Algorithm. There are many algorithms for assessing the importance of features in the machine learning domain, such as support vector machine, AdaBoost algorithm, and decision tree model. This study selected the AdaBoost algorithm in ensemble learning. The essence of the ensemble learning model is to combine many weak processors to get a better predictive processor. Ensemble learning model works well for large data set and insufficient data set. The data in this study are not sufficient. Common ensemble learning models are of two types: bagging algorithms and boosting algorithms. The boosting algorithm predicts through a series of aggregated estimated model weighted averages. AdaBoost is a representative algorithm in the boosting algorithm [29]. In this study, the input parameters were ten factors and five damage states. The damage states of individual roads are divided into five levels: none, slight, moderate, extensive, and complete [30].

The procedures of the AdaBoost algorithm can be summarized as follows:

(i) Step 1: initialize the sample weights and perform equal weight processing.

(ii) Step 2: train the base classifier. The weights are updated according to the results of each decision tree and then trained until the conditions are met.

(iii) Step 3: the weighted average method is used to combine the base classifiers into strong classifiers, and the decision trees with smaller errors are more weighted.

Base classifier: classification and regression tree classifier (maximum depth $=10$, minimum sample leaf $=5$, algorithm $=$ SAMME.R, number of estimators $=200$, and learning rate $=0.5$ ).

Due to the small data set, we chose the cross validation function in the sklearn function library to validate the model rather than dividing the data set into training set and testing set. The mean average accuracy of the output classification was 0.8204 , which was higher than the accuracy of the AdaBoost algorithm in other models [16]. Figure 3 presents the importance of the ten factors, and there are five factors that have the importance value more than $10 \%$.

3.3. Artificial Neural Network Assessment Model. In the rapid assessment after the earthquake, the assessment speed is one of the most important points. Reducing the parameters can 
TABle 4: Factors of seismic road damage.

\begin{tabular}{|c|c|c|}
\hline Factors & Classification & Features \\
\hline \multirow{5}{*}{ Highway classification } & Expressway & Better seismic performance \\
\hline & First-class & Better seismic performance \\
\hline & Second-class & \\
\hline & Third-class & Failure occurs more frequently \\
\hline & Fourth-class & Failure occurs more frequently \\
\hline \multirow{4}{*}{ Subgrade type } & No digging and no filling & No damage \\
\hline & Cutting & Destruction accounts for $26 \%$ of the total damage \\
\hline & Embankment & Destruction accounts for $28 \%$ of the total damage \\
\hline & Half-filled and half-dug & Failure occurs most frequently (48\%) \\
\hline \multirow{4}{*}{ Supporting and retaining type } & Reinforced retaining wall, prestressed cable, facing wall & Beneficial to mitigating damage \\
\hline & Gravity-type concrete & Failure occurs most frequently \\
\hline & Gravity-type wet masonry & More serious damage \\
\hline & No & Not conducive to mitigating damage \\
\hline \multirow{4}{*}{ Soil type of the site } & I & \\
\hline & II & \\
\hline & III & Intensifying the damage slightly \\
\hline & IV & Intensifying the damage \\
\hline \multirow{5}{*}{ Slope height $(h)$} & $0 \mathrm{~m}$ & The least number of damages occurred \\
\hline & $0 \mathrm{~m}<h \leq 15$ & Less destruction occurs \\
\hline & $15 \mathrm{~m}<h \leq 40 \mathrm{~m}$ & \\
\hline & $40 \mathrm{~m}<h \leq 120 \mathrm{~m}$ & More susceptible to damage \\
\hline & $120 \mathrm{~m}<h$ & More susceptible to damage \\
\hline \multirow{4}{*}{ Slope angle $(\theta)$} & $0^{\circ}$ & The least number of damages occurred \\
\hline & $0^{\circ}<\theta \leq 35^{\circ}$ & \\
\hline & $35^{\circ}<\theta \leq 65^{\circ}$ & Failure occurs most frequently \\
\hline & $65^{\circ}<\theta$ & More susceptible to damage \\
\hline \multirow{4}{*}{ Protective measure } & No, steening retaining wall & Not conducive to resisting seismic, small quantity \\
\hline & Frame beam, precast block & Beneficial to seismic \\
\hline & Hanging net and guniting, safety netting system & Can resist part of seismic \\
\hline & Shotcrete, mortar & Not conducive to resisting seismic \\
\hline \multirow{4}{*}{ Height difference of subgrade } & $h \leq 1 \mathrm{~m}$ & \\
\hline & $1 \mathrm{~m}<h \leq 3 \mathrm{~m}$ & \\
\hline & $3 \mathrm{~m}<h \leq 5 \mathrm{~m}$ & \\
\hline & $5 \mathrm{~m}<h$ & \\
\hline \multirow{4}{*}{ Seismic fortification intensity } & VI & \\
\hline & VII & \\
\hline & VIII & \\
\hline & IX & \\
\hline \multirow{6}{*}{ Practical intensity } & VI & \\
\hline & VII & \\
\hline & VIII & \\
\hline & IX & \\
\hline & $\mathrm{X}$ & \\
\hline & XI & \\
\hline
\end{tabular}

reduce the amount of data and speed up the evaluation. Therefore, we used the AdaBoost algorithm to evaluate the importance of different influencing factors. According to the results of Section 3.2, we selected the five most important factors as input parameters. We chose practical intensity, supporting and retaining type, height difference of subgrade, slope height, and soil type of the site as the input parameters. The sum of the importance value of these five parameters reached $80 \%$. Hence, we ignore other parameters when establishing the evaluation model. ANN has strong adaptive, self-learning, and nonlinear mapping capabilities, which can solve the problem of less data and uncertainty, and is not limited by nonlinear models. Earthquake is an accidental event, and destructive earthquakes have a lower probability of occurrence, such as the Wenchuan earthquake. Therefore, there are small data set on road damages and great uncertainties. Moreover, the relationship between various influencing factors of road damage and the results of damage is not clear. Above all, artificial neural networks are suitable for road damage assessment. A typical neural network includes an input layer, an implicit layer, and an output layer. The layers are fully connected, and there is no connection between the layers. The hidden layer can have one or more layers. For a typical network, a single layer of hidden layers is sufficient [13]. The input and output layers have been determined. The hidden layer selects a layer based on the actual amount of data. The number of hidden layer neurons is determined according to the following empirical equation: 


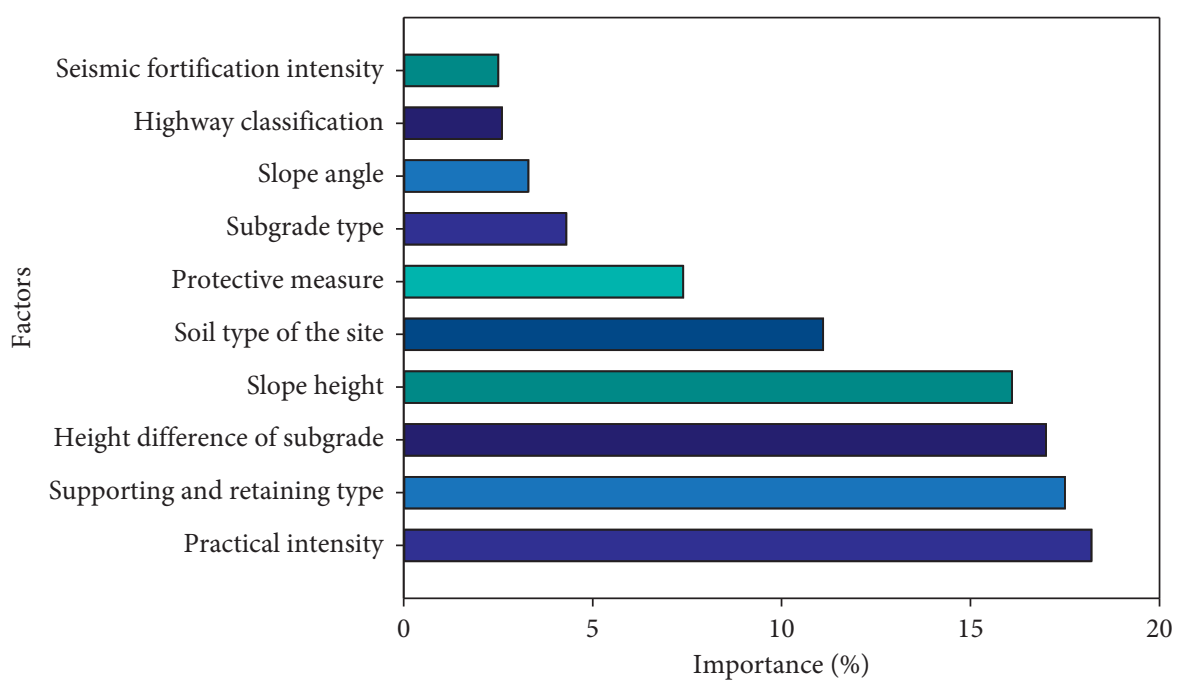

FIgURE 3: The importance values of factors of the seismic road damage based on the AdaBoost algorithm.

$$
L=\sqrt{n+m}+a
$$

where $L$ is the number of hidden layers, $n$ and $m$ are the number of input and output layers, respectively, and $a$ is a constant between 1 and 10. $n=10$ and $m=1$. We determined the number of hidden layer neurons as ten according to the convergence speed and accuracy during the training process. Therefore, this study selected the most typical three-layer backpropagation neural network, with 5 input layer neurons, 10 hidden layer neurons, and 1 output layer neuron (Figure 4). The maximum epochs were 10,000, and the learning rate was 0.1 based on the running processing and the data set. The mean square error loss function and sigmoid function were selected as the cost function (2) and activation function (3) of the hidden layer, respectively:

$$
y=\frac{1}{n} \sum(\hat{y}-t)^{2}
$$

where $y$ is the value of the cost function, $n$ presents the amount of the roads, $\hat{y}$ is the damage state of the ANN model, and $t$ is the actual damage state.

$$
f_{(x)}=\frac{1}{1+e^{-z}}
$$

where $f_{(x)}$ is the ReLU function, and $x$ is the input of the ReLU function.

We selected 50 roads as the training set and the remaining 12 roads as the testing set. The model was run in the Jupyter Notebook of the Anaconda Navigator environment with python 3 languages (https://www.anaconda. $\mathrm{com} /$ ). The accuracy of the linear model was $87 \%$ [8], while the accuracy of the ANN model was $92 \%$. It can be seen that the ANN model had a good performance in assessing road damage problems.

\section{Analysis on the Reliability of Road Networks}

According to the results of the ANN model, we could obtain the damage state of each individual road. However, it is also

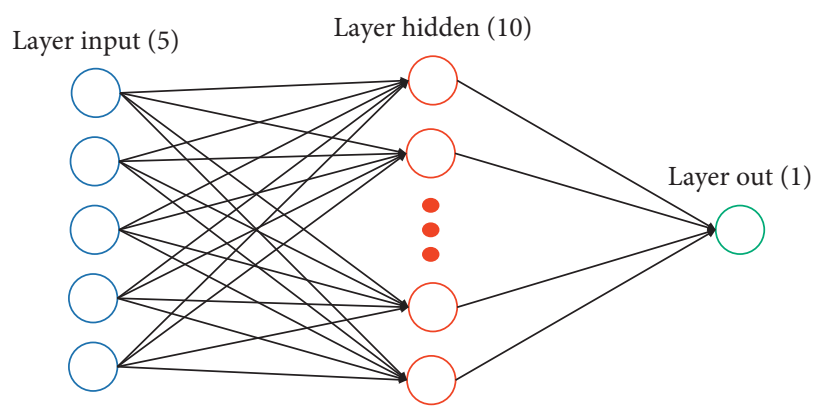

FIGURE 4: Layout for artificial neural networks for the assessment model.

necessary to consider the damage of the road network so that the road could not affect the emergency rescue after the earthquake. The combination of the damage state on the individual road and reliability of road networks can ensure that the lifeline system of emergency rescue after the earthquake is unimpeded. Therefore, we proposed the postearthquake evaluation method of the reliability of road networks.

4.1. The Pass Possibility of an Individual Road. A strong earthquake caused damage to the roads. Earthquake damage index is usually used to describe the damage degree of road, but the damage degree of earthquake is only the description of the physical damage state of road, and it cannot reflect the status of road traffic function. Therefore, it is necessary to establish the relationship between seismic damage index and pass probability. The results of Section 3.3 gave only the damage state and could not directly obtain the pass probability, $P_{r, i}$, of an individual road. Therefore, we used the damage index [31] as the conversion indicator to translate the damage state into pass possibility. Table 5 shows the relationship between the damage index and the damage state. The damage index and pass probability had a certain 
range, and we decided to use the median value of them as the value of the damage index and $P_{r, i}$.

4.2. Reliability of the Road Network Model. According to the results of the ANN model, we could obtain the damage state of each individual road. However, it is also necessary to consider the damage of the road network so that the road could not affect the emergency rescue after the earthquake. Therefore, we proposed the postearthquake evaluation method of the reliability of road networks. Urban RNC is an important decision indicator in urban road network planning and construction [4]. The RNC represents the maximum traffic volume and provides important information for effective traffic flow control and demand management. The $\mathrm{RNC}$ is the maximum flow rate determined according to the geometric characteristics of the road, traffic conditions, and specified operational characteristics, and its value has relative stability and prescriptiveness. The simplest consideration for RNC is to add up the maximum capacity of all road links to get the physical capacity of an urban transportation network. Under the general road and traffic conditions of the city and when not affected by the intersection of planes, the possible RNC, $N_{P}$, can be computed by [32]

$$
N_{P}=\frac{3600}{\delta_{i}}
$$

where $\delta_{i}$ is the average traffic interval between consecutive traffic. When the city does not have the value of $\delta_{i}$, the road capacity can use the value in Table 6 .

According to the code for design of urban road engineering, in road capacity design, the actual capacity of the road is not allowed to reach the maximum capacity value. Instead, it tends to reduce the maximum capacity as the design value for safety. The higher the level of the road, the greater the reduction coefficient. When the RNC is not affected by a plane intersection, the design RNC, $N_{i 0}$, can be computed by

$$
N_{i 0}=a_{c} \times N_{P}
$$

where $a_{c}$ is the road classification coefficient of the vehicle lane (Table 7).

The initial RNC, $N_{0}$, before the earthquake is defined as follows:

$$
N_{0}=\sum_{i=1}^{n} Z_{i} \times N_{i 0}
$$

where $Z_{i}$ is the importance index of the $i$-th road, which mainly reflects the importance or influence of the road in the network. The urban road network consists of several road sections, but each road section has different importance in the whole road network. Some road sections have high utilization rate, and some are very low. The impact of these unit sections on the connectivity of the entire road network is not the same. Therefore, the weight of the unit road link needs to be calibrated. The index $Z_{i}$ is usually calculated based on the betweenness centrality. However, the betweenness centrality involves calculation in a complex
TABLE 5: The relationship between the damage index and the damage state.

\begin{tabular}{lclc}
\hline $\begin{array}{l}\text { Damage } \\
\text { state }\end{array}$ & Damage index $(I)$ & Pass state & $\begin{array}{c}\text { Pass probability } \\
(p)\end{array}$ \\
\hline None & $0.00 \leq I<0.10$ & Allowable & $0.90<p \leq 1.00$ \\
Slight & $0.10 \leq I<0.30$ & Limitation & $0.70<p \leq 0.90$ \\
Moderate & $0.30 \leq I<0.55$ & Limitation & $0.45<p \leq 0.70$ \\
Extensive & $0.55 \leq I<0.85$ & Unallowed & $p \leq 0.001$ \\
Complete & $0.85 \leq I \leq 1.00$ & Unallowed & $p \leq 0.001$ \\
\hline
\end{tabular}

TABle 6: Possible capacity of the road [32].

\begin{tabular}{lcccc}
\hline Calculated driving speed $(\mathrm{km} / \mathrm{h})$ & 50 & 40 & 30 & 20 \\
\hline$N_{P}(\mathrm{pcu} / \mathrm{h})$ & 1690 & 1640 & 1550 & 1380 \\
\hline
\end{tabular}

network [33]. Hence, the index $Z_{i}$ can be expressed as (7) for the convenience of calculation and speed of the assessment:

$$
Z_{i}=\frac{B_{i}}{B_{t} \quad}
$$

where $B_{i}$ is the number of road links connected to the $i$-th road link and $B_{t} \quad{ }_{d}$ is the total number of road links. If the road link contains bridges, tunnels, etc., the pass probability $P_{r, i}$ is obtained based on the ANN model, and the RNC after the earthquake can be obtained by (8). The reliability of the road network, $R$, is defined as the ratio of $N$ to $N_{0}(9)$. Table 8 presents the reliability state of the road network, including reliable, medium reliable, and unreliable.

$$
\begin{aligned}
N & =\sum_{i=1}^{n} P_{r, i} \times Z_{i} \times N_{i 0}, \\
R & =\frac{N}{N_{0}} .
\end{aligned}
$$

\section{Case Study Results}

The methodology proposed in this paper is applied to the Karamay district in Karamay city, China. Due to the lack of information on the roads of all cities and for the propose of demonstrating the method proposed in this study, the reliability of road networks is applied to the area enclosed by the Zhunger road, Xihuan road, Nanhuan road, and Donghuan road, as shown in Figure 5. The road network contains 64 road links and 39 nodes, totaling $60 \mathrm{~km}$ (Table 9).

According to the artificial neural network assessment model obtained in Section 3, the failure states of all units in the road network under different earthquake intensities can be obtained, and the seismic damage index for each road is shown in Table 10 .

The reliability of each road link under different seismic intensities is obtained based on Section 4.1. Figure 6 presents the road network reliability with the intensity of VI, VII, VIII, and IX, respectively. From the figure, it can be observed that the reliability of the road network in intensity VI is very 
TABLe 7: Coefficient of the road classification [24].

\begin{tabular}{lcccc}
\hline Road classification & Expressway & Arterial road & Minor arterial road & Branch road \\
\hline$a_{c}$ & 0.75 & 0.80 & 0.85 & 0.90 \\
\hline
\end{tabular}

TABLE 8: The reliability state of the road network.

\begin{tabular}{lccc}
\hline Reliability state & Reliable & Medium reliable & Unreliable \\
\hline Reliability of the road network & $R \geq 0.8$ & $0.5 \leq R<0.8$ & $R<0.5$ \\
\hline
\end{tabular}

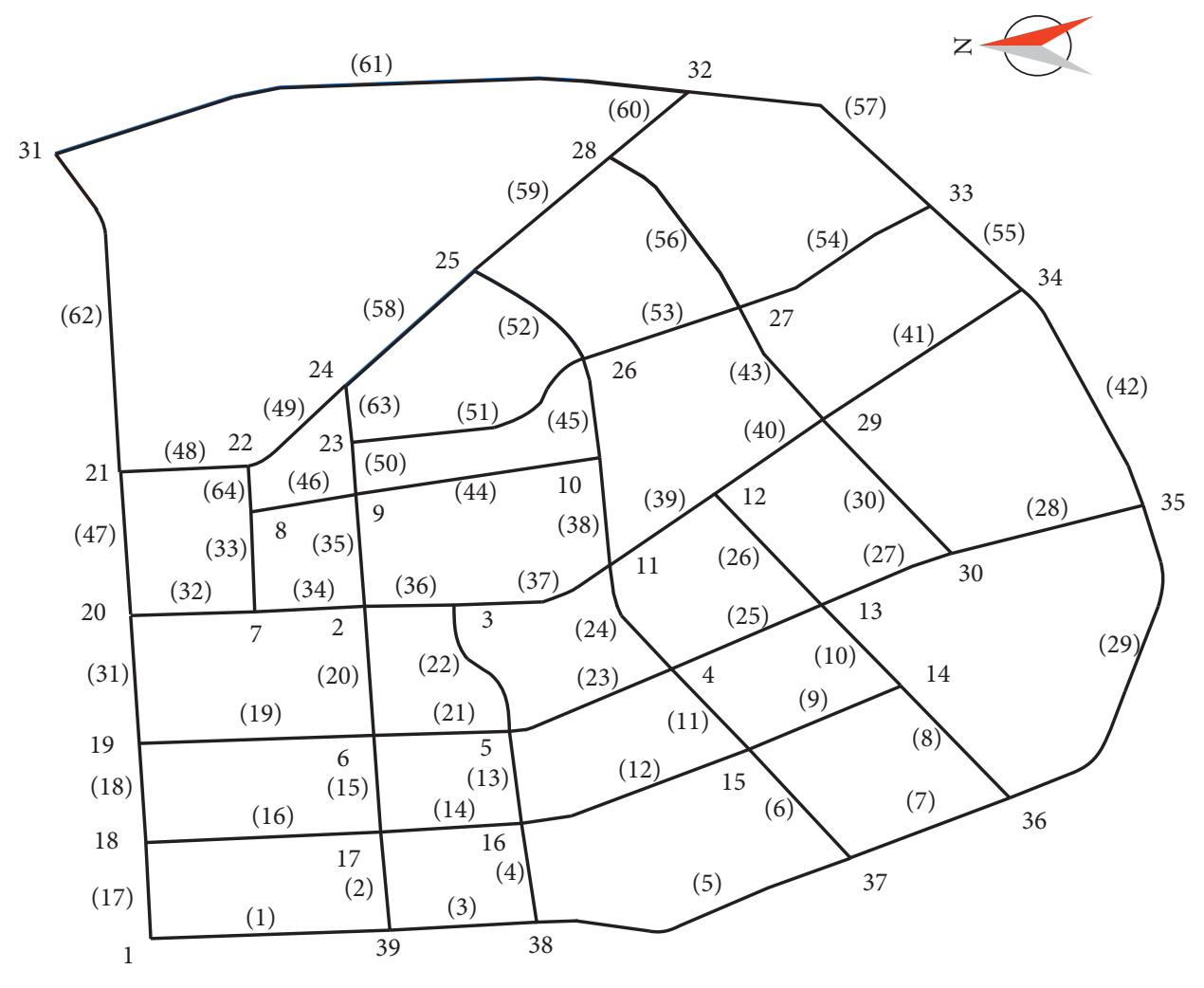

FIgURE 5: Road network plan.

TABle 9: Properties of the road network.

\begin{tabular}{|c|c|c|c|c|c|c|}
\hline Road links & Vertex $i$ & Vertex $j$ & Name & Road classification & Length $(\mathrm{m})$ & Year built \\
\hline 1 & 1 & 39 & Xihuan road & Arterial road & 1112 & 2000 \\
\hline 2 & 17 & 39 & Kunlun road & Arterial road & 682 & 2003 \\
\hline 3 & 38 & 39 & Xihuan road & Arterial road & 697 & 2000 \\
\hline 4 & 16 & 38 & Xingfu road & Arterial road & 701 & 2002 \\
\hline 5 & 37 & 38 & Xihuan road & Arterial road & 1625 & 2000 \\
\hline 6 & 15 & 37 & Nanxin road & Arterial road & 903 & 2002 \\
\hline 7 & 36 & 37 & Xihuan road & Arterial road & 864 & 2000 \\
\hline 8 & 14 & 36 & Shiji road & Arterial road & 942 & 2003 \\
\hline 9 & 14 & 15 & Youjian road & Minor arterial road & 846 & 2003 \\
\hline 10 & 13 & 14 & Shiji road & Arterial road & 685 & 2003 \\
\hline 11 & 4 & 15 & Nanxin road & Arterial road & 675 & 2002 \\
\hline 12 & 15 & 16 & Youjian road & Minor arterial road & 1190 & 2003 \\
\hline 13 & 5 & 16 & Xingfu road & Arterial road & 651 & 2002 \\
\hline 14 & 16 & 17 & Youjian road & Minor arterial road & 670 & 2003 \\
\hline 15 & 6 & 17 & Kunlun road & Arterial road & 681 & 2003 \\
\hline 16 & 17 & 18 & Youjian road & Minor arterial road & 1108 & 2003 \\
\hline
\end{tabular}


TABle 9: Continued.

\begin{tabular}{|c|c|c|c|c|c|c|}
\hline Road links & Vertex $i$ & Vertex $j$ & Name & Road classification & Length $(\mathrm{m})$ & Year built \\
\hline 17 & 1 & 18 & Zhunger road & Arterial road & 680 & 2003 \\
\hline 18 & 18 & 19 & Zhunger road & Arterial road & 700 & 2003 \\
\hline 19 & 6 & 19 & Youyi road & Arterial road & 1106 & 2003 \\
\hline 20 & 2 & 6 & Kunlun road & Arterial road & 914 & 2003 \\
\hline 21 & 5 & 6 & Youyi road & Arterial road & 640 & 2003 \\
\hline 22 & 3 & 5 & Xingfu road & Arterial road & 964 & 2002 \\
\hline 23 & 4 & 5 & Yingbin road & Arterial road & 884 & 2000 \\
\hline 24 & 4 & 11 & Nanxin road & Arterial road & 802 & 2002 \\
\hline 25 & 4 & 13 & Yingbin road & Arterial road & 833 & 2000 \\
\hline 26 & 12 & 13 & Shiji road & Arterial road & 929 & 2003 \\
\hline 27 & 13 & 30 & Yingbin road & Arterial road & 717 & 2000 \\
\hline 28 & 30 & 35 & Yingbin road & Arterial road & 955 & 2000 \\
\hline 29 & 35 & 36 & Xihuan road & Arterial road & 2322 & 2000 \\
\hline 30 & 29 & 30 & Baoshi road & Minor arterial road & 1124 & 2012 \\
\hline 31 & 19 & 20 & Zhunger road & Arterial road & 916 & 2003 \\
\hline 32 & 7 & 20 & Shengli road & Arterial road & 592 & 2003 \\
\hline 33 & 7 & 8 & Ashan road & Minor arterial road & 702 & 2004 \\
\hline 34 & 2 & 7 & Shengli road & Arterial road & 512 & 2003 \\
\hline 35 & 2 & 9 & Kunlun road & Arterial road & 802 & 2003 \\
\hline 36 & 2 & 3 & Shengli road & Arterial road & 515 & 2003 \\
\hline 37 & 2 & 11 & Shengli road & Arterial road & 843 & 2003 \\
\hline 38 & 10 & 11 & Nanxin road & Arterial road & 766 & 2002 \\
\hline 39 & 11 & 12 & Shengli road & Arterial road & 696 & 2003 \\
\hline 40 & 12 & 29 & Shengli road & Arterial road & 736 & 2003 \\
\hline 41 & 29 & 34 & Shengli road & Arterial road & 1309 & 2003 \\
\hline 42 & 34 & 35 & Nanhuan road & Arterial road & 1633 & 2012 \\
\hline 43 & 27 & 29 & Baoshi road & Minor arterial road & 889 & 2012 \\
\hline 44 & 9 & 10 & Dongjiao road & Minor arterial road & 1171 & 2004 \\
\hline 45 & 10 & 26 & Nanxin road & Arterial road & 707 & 2002 \\
\hline 46 & 8 & 9 & Dongjiao road & Minor arterial road & 512 & 2004 \\
\hline 47 & 20 & 21 & Zhunger road & Arterial road & 1013 & 2003 \\
\hline 48 & 21 & 22 & Changzheng road & Arterial road & 599 & 2004 \\
\hline 49 & 22 & 24 & Jinyuan road & Arterial road & 754 & 2000 \\
\hline 50 & 9 & 23 & Kunlun road & Arterial road & 370 & 2003 \\
\hline 51 & 23 & 26 & Baihua road & Minor arterial road & 1338 & 2004 \\
\hline 52 & 25 & 26 & Nanxin road & Arterial road & 822 & 2002 \\
\hline 53 & 26 & 27 & Baihua road & Minor arterial road & 820 & 2004 \\
\hline 54 & 27 & 33 & Ruyi road & Minor arterial road & 1160 & 2004 \\
\hline 55 & 33 & 34 & Nanhuan road & Arterial road & 724 & 2012 \\
\hline 56 & 27 & 28 & Baoshi road & Minor arterial road & 1244 & 2012 \\
\hline 57 & 32 & 33 & Nanhuan road & Arterial road & 1503 & 2012 \\
\hline 58 & 24 & 25 & Jinyuan road & Arterial road & 1009 & 2000 \\
\hline 59 & 25 & 28 & Jinyuan road & Arterial road & 1009 & 2000 \\
\hline 60 & 28 & 32 & Jinyuan road & Arterial road & 608 & 2000 \\
\hline 61 & 31 & 32 & Donghuan road & Arterial road & 3091 & 2000 \\
\hline 62 & 21 & 31 & Zhunger road & Arterial road & 2303 & 2003 \\
\hline 63 & 23 & 24 & Kunlun road & Arterial road & 411 & 2003 \\
\hline 64 & 8 & 22 & Ashan road & Minor arterial road & 316 & 2004 \\
\hline
\end{tabular}

large. With the increase of the seismic intensity, the probabilities of the road network at medium reliable and unreliable become more obvious.

(1) When the seismic intensity is VI, only one road link is in medium reliable. The RNC is almost unaffected, and the traffic order is normal, which can ensure that people can quickly resume normal work and life.

(2) When the seismic intensity is VII, there are $14 \%$ of the road links which are in medium reliable, and the rest are in the reliable state. There are no unreliable road links, and the RNC is affected to some extent.
The whole transportation function is intact, and relief supplies and ambulance personnel can enter the disaster area at the first time. The normal traffic can be restored after a short period of time.

(3) When the seismic intensity is VIII, there are 59\%, $30 \%$, and $11 \%$ of the road links which are in the reliable, medium reliable, and unreliable state, respectively. Some road links have lost the RNC, but they can still meet emergency rescue needs.

(4) When the seismic intensity is IX, there are $44 \%, 33 \%$, and $23 \%$ of the road links which are in the reliable, 
TABle 10: Damage state of elements in the network.

\begin{tabular}{|c|c|c|c|c|c|c|c|}
\hline $\begin{array}{l}\text { Road } \\
\text { links }\end{array}$ & $\begin{array}{c}\text { Vertex } \\
i\end{array}$ & $\begin{array}{c}\text { Vertex } \\
j\end{array}$ & Name & VI & VII & VIII & IX \\
\hline 1 & 1 & 39 & Xihuan road & 0.05 & 0.11 & 0.32 & 0.63 \\
\hline 2 & 17 & 39 & Kunlun road & 0.01 & 0.03 & 0.04 & 0.09 \\
\hline 3 & 38 & 39 & Xihuan road & 0.02 & 0.04 & 0.08 & 0.15 \\
\hline 4 & 16 & 38 & Xingfu road & 0.01 & 0.05 & 0.12 & 0.30 \\
\hline 5 & 37 & 38 & Xihuan road & 0.04 & 0.09 & 0.23 & 0.43 \\
\hline 6 & 15 & 37 & Nanxin road & 0.11 & 0.34 & 0.56 & 0.87 \\
\hline 7 & 36 & 37 & Xihuan road & 0.04 & 0.07 & 0.21 & 0.36 \\
\hline 8 & 14 & 36 & Shiji road & 0.03 & 0.06 & 0.09 & 0.18 \\
\hline 9 & 14 & 15 & Youjian road & 0.04 & 0.07 & 0.22 & 0.37 \\
\hline 10 & 13 & 14 & Shiji road & 0.03 & 0.06 & 0.09 & 0.18 \\
\hline 11 & 4 & 15 & Nanxin road & 0.14 & 0.36 & 0.63 & 0.95 \\
\hline 12 & 15 & 16 & Youjian road & 0.04 & 0.07 & 0.24 & 0.42 \\
\hline 13 & 5 & 16 & Xingfu road & 0.11 & 0.33 & 0.61 & 0.91 \\
\hline 14 & 16 & 17 & Youjian road & 0.01 & 0.04 & 0.09 & 0.27 \\
\hline 15 & 6 & 17 & Kunlun road & 0.04 & 0.07 & 0.20 & 0.43 \\
\hline 16 & 17 & 18 & Youjian road & 0.04 & 0.08 & 0.27 & 0.46 \\
\hline 17 & 1 & 18 & Zhunger road & 0.06 & 0.13 & 0.32 & 0.57 \\
\hline 18 & 18 & 19 & Zhunger road & 0.12 & 0.38 & 0.59 & 0.93 \\
\hline 19 & 6 & 19 & Youyi road & 0.13 & 0.39 & 0.62 & 0.95 \\
\hline 20 & 2 & 6 & Kunlun road & 0.06 & 0.15 & 0.33 & 0.61 \\
\hline 21 & 5 & 6 & Youyi road & 0.06 & 0.14 & 0.32 & 0.60 \\
\hline 22 & 3 & 5 & Xingfu road & 0.02 & 0.08 & 0.13 & 0.29 \\
\hline 23 & 4 & 5 & Yingbin road & 0.01 & 0.03 & 0.08 & 0.18 \\
\hline 24 & 4 & 11 & Nanxin road & 0.01 & 0.02 & 0.06 & 0.13 \\
\hline 25 & 4 & 13 & Yingbin road & 0.01 & 0.02 & 0.06 & 0.13 \\
\hline 26 & 12 & 13 & Shiji road & 0.01 & 0.02 & 0.07 & 0.15 \\
\hline 27 & 13 & 30 & Yingbin road & 0.01 & 0.02 & 0.06 & 0.14 \\
\hline 28 & 30 & 35 & Yingbin road & 0.02 & 0.04 & 0.08 & 0.18 \\
\hline 29 & 35 & 36 & Xihuan road & 0.02 & 0.04 & 0.08 & 0.18 \\
\hline 30 & 29 & 30 & Baoshi road & 0.02 & 0.05 & 0.13 & 0.30 \\
\hline 31 & 19 & 20 & Zhunger road & 0.12 & 0.38 & 0.59 & 0.93 \\
\hline 32 & 7 & 20 & Shengli road & 0.04 & 0.08 & 0.22 & 0.41 \\
\hline 33 & 7 & 8 & Ashan road & 0.04 & 0.08 & 0.22 & 0.41 \\
\hline 34 & 2 & 7 & Shengli road & 0.01 & 0.02 & 0.04 & 0.10 \\
\hline 35 & 2 & 9 & Kunlun road & 0.06 & 0.15 & 0.33 & 0.61 \\
\hline 36 & 2 & 3 & Shengli road & 0.04 & 0.07 & 0.22 & 0.37 \\
\hline 37 & 2 & 11 & Shengli road & 0.01 & 0.03 & 0.06 & 0.15 \\
\hline 38 & 10 & 11 & Nanxin road & 0.06 & 0.15 & 0.33 & 0.61 \\
\hline 39 & 11 & 12 & Shengli road & 0.01 & 0.02 & 0.05 & 0.14 \\
\hline 40 & 12 & 29 & Shengli road & 0.01 & 0.02 & 0.05 & 0.14 \\
\hline 41 & 29 & 34 & Shengli road & 0.01 & 0.02 & 0.05 & 0.14 \\
\hline 42 & 34 & 35 & Nanhuan road & 0.02 & 0.04 & 0.08 & 0.18 \\
\hline 43 & 27 & 29 & Baoshi road & 0.08 & 0.25 & 0.48 & 0.77 \\
\hline 44 & 9 & 10 & Dongjiao road & 0.01 & 0.04 & 0.09 & 0.27 \\
\hline 45 & 10 & 26 & Nanxin road & 0.01 & 0.02 & 0.04 & 0.10 \\
\hline 46 & 8 & 9 & Dongjiao road & 0.01 & 0.04 & 0.09 & 0.27 \\
\hline 47 & 20 & 21 & Zhunger road & 0.19 & 0.40 & 0.71 & 0.98 \\
\hline 48 & 21 & 22 & $\begin{array}{l}\text { Changzheng } \\
\text { road }\end{array}$ & 0.01 & 0.02 & 0.06 & 0. \\
\hline 49 & 22 & 24 & Jinyuan road & 0.01 & 0.02 & 0.06 & 0.12 \\
\hline 50 & 9 & 23 & Kunlun road & 0.01 & 0.02 & 0.06 & 0.12 \\
\hline 51 & 23 & 26 & Baihua road & 0.01 & 0.04 & 0.09 & 0.27 \\
\hline 52 & 25 & 26 & Nanxin road & 0.01 & 0.02 & 0.04 & 0.10 \\
\hline 53 & 26 & 27 & Baihua road & 0.01 & 0.04 & 0.09 & 0.27 \\
\hline 54 & 27 & 33 & Ruyi road & 0.01 & 0.04 & 0.09 & 0.27 \\
\hline 55 & 33 & 34 & Nanhuan road & 0.02 & 0.04 & 0.08 & 0.18 \\
\hline 56 & 27 & 28 & Baoshi road & 0.08 & 0.25 & 0.48 & 0.77 \\
\hline 57 & 32 & 33 & Nanhuan road & 0.02 & 0.04 & 0.08 & 0.18 \\
\hline 58 & 24 & 25 & Jinyuan road & 0.01 & 0.02 & 0.06 & 0.12 \\
\hline
\end{tabular}

TABLE 10: Continued.

\begin{tabular}{lccccccc}
\hline $\begin{array}{l}\text { Road } \\
\text { links }\end{array}$ & $\begin{array}{c}\text { Vertex } \\
i\end{array}$ & $\begin{array}{c}\text { Vertex } \\
j\end{array}$ & Name & VI & VII & VIII & IX \\
\hline 59 & 25 & 28 & Jinyuan road & 0.01 & 0.02 & 0.06 & 0.12 \\
60 & 28 & 32 & Jinyuan road & 0.01 & 0.02 & 0.06 & 0.12 \\
61 & 31 & 32 & $\begin{array}{c}\text { Donghuan } \\
\text { road }\end{array}$ & 0.01 & 0.02 & 0.05 & 0.14 \\
62 & 21 & 31 & Zhunger road & 0.01 & 0.02 & 0.05 & 0.14 \\
63 & 23 & 24 & Kunlun road & 0.01 & 0.02 & 0.06 & 0.12 \\
64 & 8 & 22 & Ashan road & 0.01 & 0.02 & 0.06 & 0.12 \\
\hline
\end{tabular}

medium reliable, and unreliable state, respectively. Some road links are blocked and difficult to pass, which is mainly due to the safety distance between the buildings on both sides, and the road is not enough. The debris piling after the collapse of the buildings has a great impact on the RNC. Fortunately, most of the buildings and the roads have sufficient safety distance, and the road conditions are good due to the reasonable planning of the Karamay district. Hence, there are about half of the road links which are in the reliable state under intensity IX.

We calculated the number of roads connected to each road and the importance index and obtained the RNC before and after the earthquake. Then, the road network reliability under different seismic intensities can be obtained as shown in Table 11.

\section{Discussion and Future Works}

The rescue time after the earthquakes is crucial. The shorter the time to predict the roads, the faster the rescuer can reach the disaster area, which can greatly reduce casualties and economic losses. Therefore, it is necessary to select suitable factors to assess the roads, which can save the time of collecting data and obtaining suitable accuracy. In this study, we first select ten factors that affect road damage and analyzed their importance using the AdaBoost algorithm. Among ten factors of the road damage, the practical intensity, supporting and retaining type, height difference of subgrade, slope height, and soil type of the site are more important than the others. We chose the five factors as the input variables of the ANN assessment model. The accuracy is more than the regression model [8]. However, the model only considers the data of the Wenchuan earthquake and ignores some factors, such as soil liquefaction, secondary disasters, and economic conditions. Whether the foundation soil in the earthquake is liquefied, it is related to the gravel content, the buried depth of gravel soil, the depth of groundwater, and the seismic intensity [34]. The liquefaction phenomenon does not occur until the earthquake occurs, which is a complex phenomenon, and there is no suitable method to evaluate in a few minutes [3]. Most of the current methods are field surveys. Similarly, secondary disasters also have such problems, and it is unreasonable to use only numerical simulations to predict them [18]. In areas with more developed economies, the more developed the 


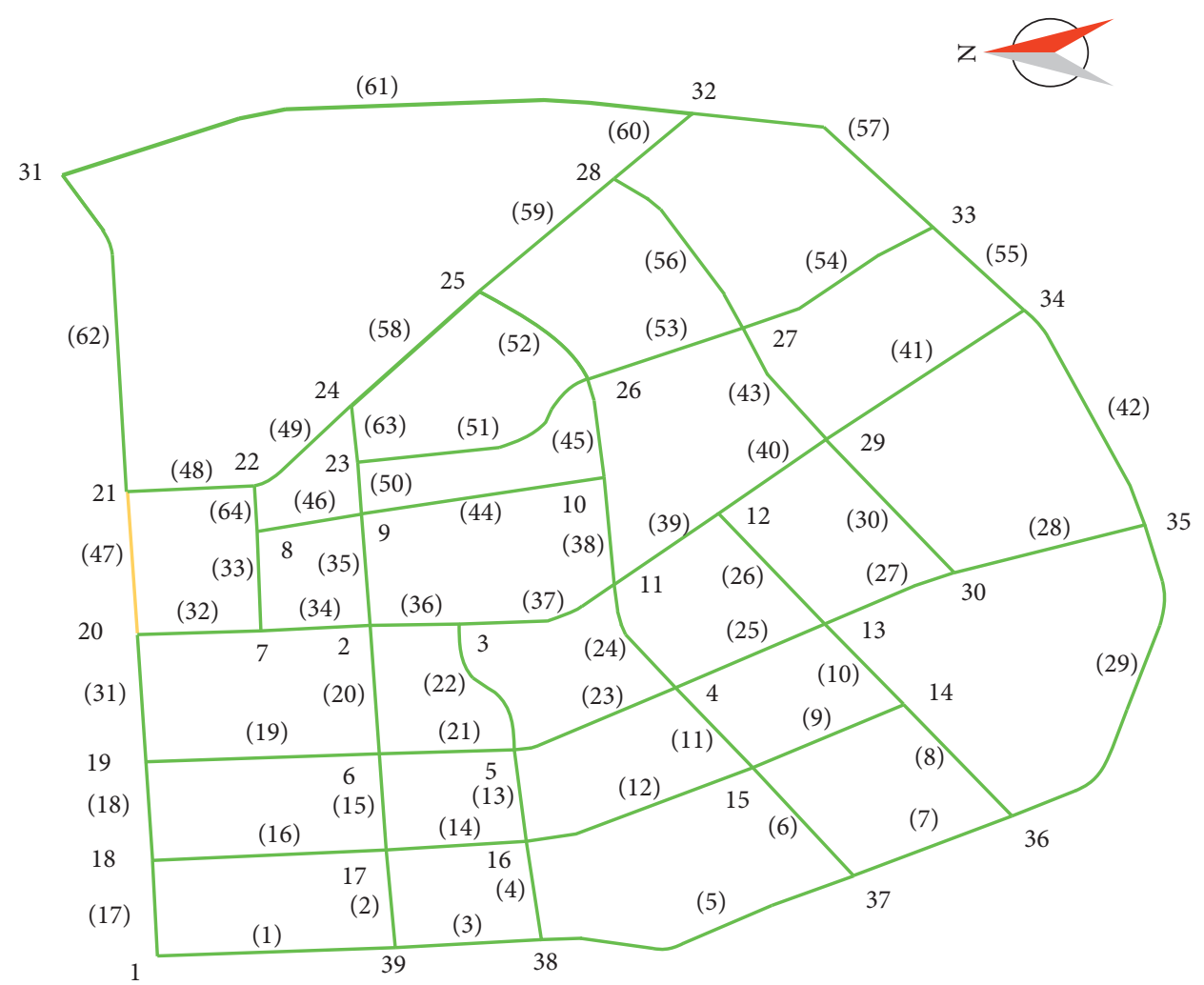

(a)

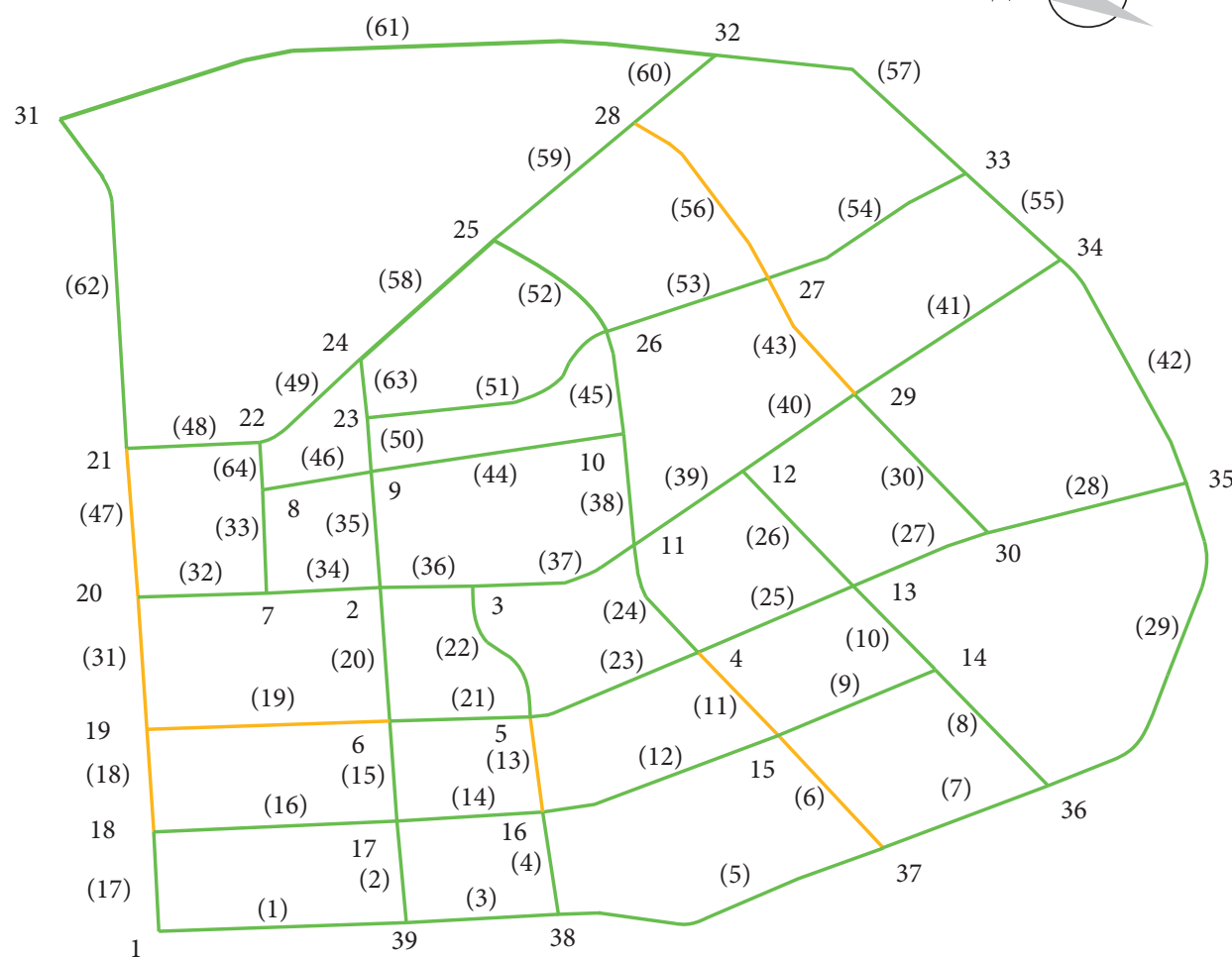

(b)

Figure 6: Continued. 


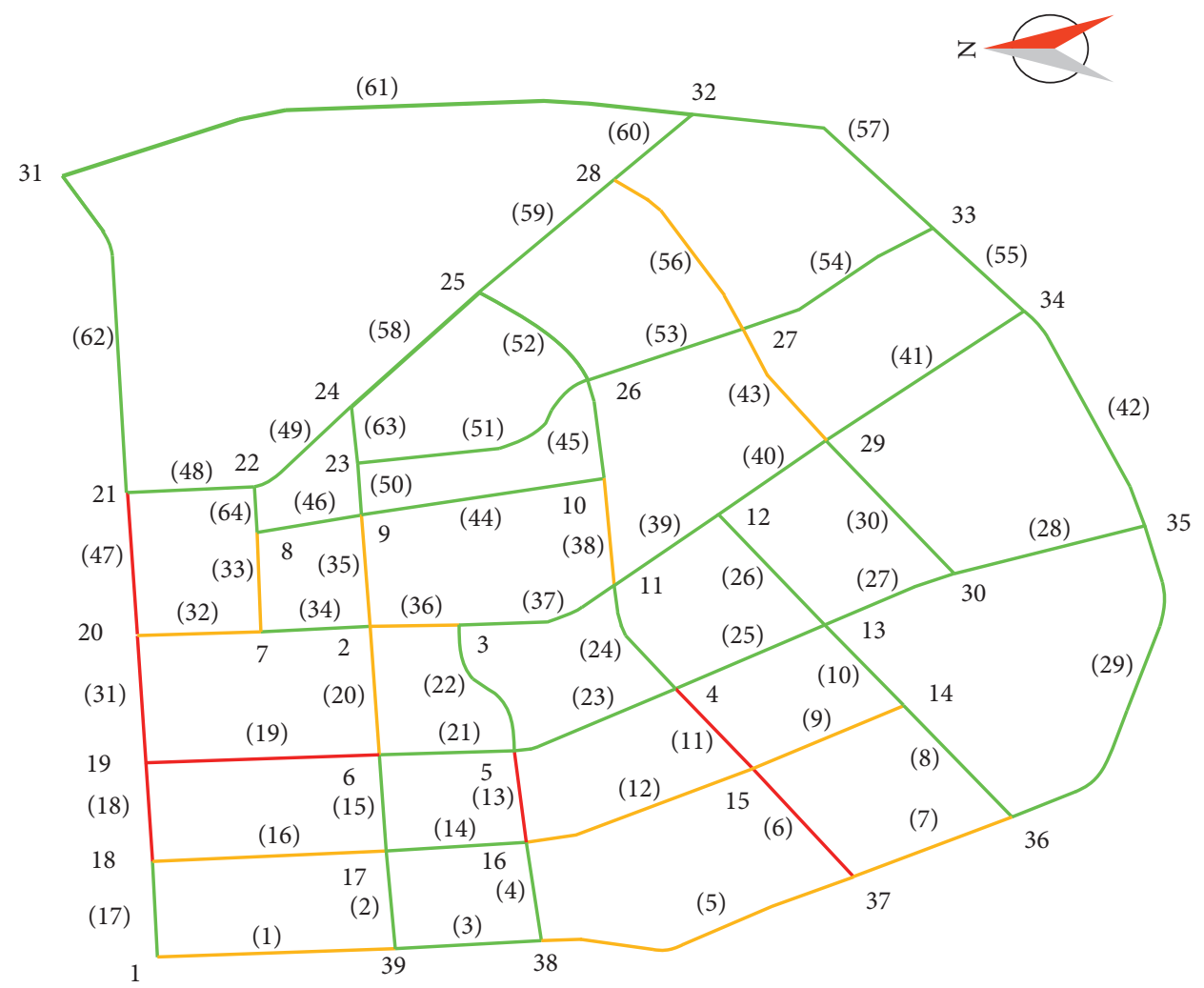

(c)

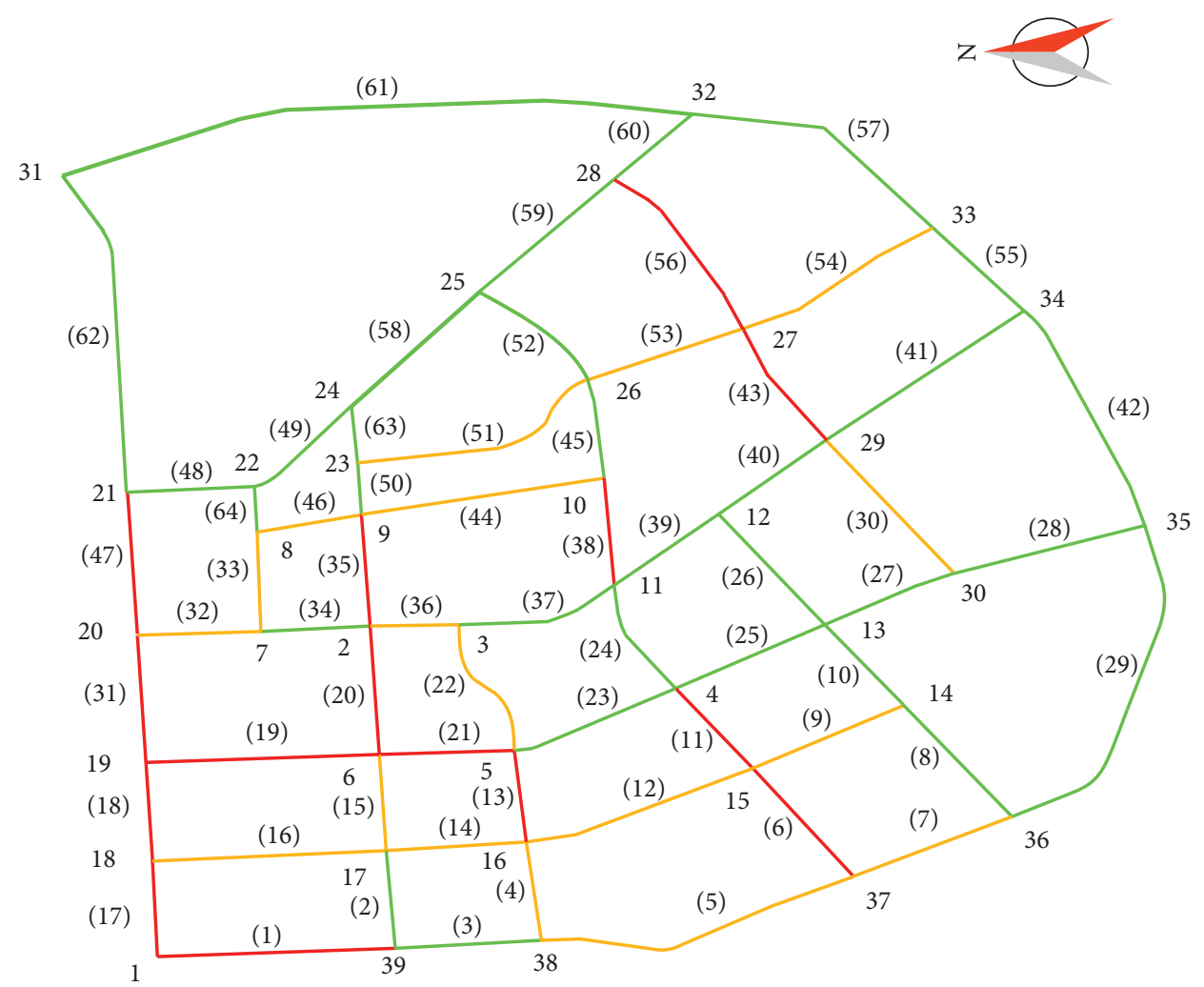

(d)

FIGURE 6: Road network reliability diagram under different seismic intensities: (a) VI; (b) VII; (c) VIII; (d) IX. Green lines represent the road links being in the reliable state, yellow represents medium reliable, and red represents unreliable. 
TABLE 11: The reliability value corresponding to the seismic intensity of the road network in the Karamay district.

\begin{tabular}{lcccc}
\hline $\begin{array}{l}\text { Seismic } \\
\text { intensity }\end{array}$ & VI & VII & VIII & IX \\
\hline$R$ & 0.9299 & 0.8941 & $\begin{array}{c}0.7543 \\
\text { Medium } \\
\text { reliable }\end{array}$ & $\begin{array}{c}0.6631 \\
\text { Medium } \\
\text { reliable }\end{array}$ \\
\hline
\end{tabular}

construction technology, the higher the level of safety of the corresponding roads. The problems in the evaluation of economic conditions are the lack of information, and some data come from many years ago. Annual inflation affects economic conditions [35], so previous data may not apply to the present. Moreover, the small data sets influence the accuracy and applicability of the ANN model. The damage data of the road networks should be further collected in the future earthquakes.

The methodology proposed is more convenient for calculating the reliability of the networks, the speed is faster, and the parameters considered are less than the previous studies $[2,3,5]$. In the evaluation of the road network, we use the median value of the range given by the standard [27] for both the seismic damage index and the pass probability. This part should be optimized in future research to make the predictions more accurate. According to the data, the actual number of earthquake damages is positively correlated with the increase of seismic intensity. The intensity is determined by the macroscopic phenomenon of earthquake damage and the statistical results. The assessment is subjective and ambiguous, and the model using seismic parameters as seismic inputs should be developed, such as the occurrence time, magnitude, and earthquake peak acceleration [10]. Moreover, the method proposed in this study can only evaluate static damage states and road reliability. The dynamic reliability of the road networks ought to be further investigated to reflect the real-time traffic behavior after earthquakes.

\section{Conclusions}

This paper presents a method to assess the reliability of the road networks considering the factors' importance, damage index, pass possibility, and traffic capacity after the earthquakes. This method is developed based on the machine learning algorithms and linear model. The conclusions of the methodology are as follows: (1) the changes in the practical intensity, supporting and retaining type, height difference of subgrade, slope height, and soil type of the site have a greater impact on the damage of the road. These factors should be considered for the assessment model of the road damage; (2) the seismic intensity has a strong correlation with the damage of the road networks. The greater the seismic intensity, the lower the reliability of the road network and the more serious the damage to the road; and (3) the proposed methodology has a good performance on the evaluation of the road networks. It can be seen that the assessment on the network damages should first consider the individual structure and then calculate the networks.

\section{Data Availability}

The data used to support the findings of this study are available from the corresponding author upon request.

\section{Conflicts of Interest}

The authors declare that they have no conflicts of interest.

\section{Authors' Contributions}

The work in this manuscript was done with the participation of all the authors. Dr. Jinlong Liu was the main planner of the manuscript. The artificial neural network assessment model for an individual road and the analysis model for the reliability of road networks were mainly built by Dr. Liu. However, Ph.D. student Hanxi Jia has also done important work. She was mainly responsible for collecting data of road damage in the Wenchuan earthquake and accomplishing the assessment of the factor importance using the AdaBoost Algorithm. Professor Lin gave them a lot of advice on road damage assessment, and he reviewed the case study results in detail. Postgraduate Heng Hu provided them with detailed data of the road network in Section 5 and helped them to complete the road network reliability analysis.

\section{Acknowledgments}

The authors are very grateful to Professor Junqi Lin for his help. This work was supported by the National Key Technology R\&D Program of China (grant no. 2018YFC1504401) and the Heilongjiang Provincial Key Laboratory of Underground Engineering Technology Open Project of China (grant no. 2017-HXYKF-06).

\section{References}

[1] C. A. Davis, A. Mostafavi, and H. Wang, "Establishing characteristics to operationalize resilience for lifeline systems," Natural Hazards Review, vol. 19, no. 4, Article ID 04018014, 2018.

[2] P. Bocchini and D. M. Frangopol, "A stochastic computational framework for the joint transportation network fragility analysis and traffic flow distribution under extreme events," Probabilistic Engineering Mechanics, vol. 26, no. 2, pp. 182193, 2011.

[3] A. Kiremidjian, J. Moore, Y. Y. Fan, O. Yazlali, N. Basoz, and M. Williams, "Seismic risk assessment of transportation network systems," Journal of Earthquake Engineering, vol. 11, no. 3, pp. 371-382, 2007.

[4] A. Guo, Z. Liu, S. Li, and H. Li, "Seismic performance assessment of highway bridge networks considering post-disaster traffic demand of a transportation system in emergency conditions," Structure and Infrastructure Engineering, vol. 13, no. 12, pp. 1523-1537, 2017.

[5] L. Cheng, M. Du, X. Jiang, and H. Rakha, "Modeling and estimating the capacity of urban transportation network with rapid transit,” Transport, vol. 29, no. 2, pp. 165-174, 2014.

[6] Y. Ji, R. G. Mishalani, and M. R. McCord, "Estimating transit route OD flow matrices from APC data on multiple bus trips using the IPF method with an iteratively improved base: 
method and empirical evaluation," Journal of Transportation Engineering, vol. 140, no. 5, Article ID 04014008, 2014.

[7] X. Zhou, M. Venigalla, and S. Zhu, "Bounding box approach to network pruning for efficient path search through large networks," Journal of Computing in Civil Engineering, vol. 31, no. 5, Article ID 04017033, 2017.

[8] H. Heng, "Research on assessment method of road seismic damage based on the Wenchuan earthquake," Institute of Engineering Mechanics, China Earthquake Administration, Beijing, China, 2018.

[9] Q. Yu and R. Tian, "Research on reversal lane application method of urban road network based on the Bi-level programming," Advances in Intelligent Systems and Computing, Springer, vol. 279, pp. 983-992, Berlin, Germany, 2014.

[10] K. Pitilakis, S. Argyroudis, K. Kakderi, and J. Selva, "Systemic vulnerability and risk assessment of transportation systems under natural hazards towards more resilient and robust infrastructures," Transportation Research Procedia in Proceedings of the 6th Transportation Research Arena, vol. 14, pp. 1335-1344, Warsaw, Poland, April 2016.

[11] P. Gauthier, A. Furno, and N.-E. El Faouzi, "Road network resilience: how to identify critical links subject to day-to-day disruptions," Transportation Research Record: Journal of the Transportation Research Board, vol. 2672, no. 1, pp. 54-65, 2018.

[12] H. Hu, J. Lin, and J. Liu, "Improved methodology for seismic estimation of highway based on Wenchuan earthquake," in Proceedings of the 2018 International Conference on Modeling, Simulation and Optimization, pp. 291-296, Xiamen, China, November 2018.

[13] Y. Lecun, Y. Bengio, and G. Hinton, “Deep learning," Nature, vol. 521, no. 7553, pp. 436-444, 2015.

[14] P.-j. Chun, H. Yamashita, and S. Furukawa, "Bridge damage severity quantification using multipoint acceleration measurement and artificial neural networks," Shock and Vibration, vol. 2015, Article ID 789384, 11 pages, 2015.

[15] K. Morfidis and K. Kostinakis, "Approaches to the rapid seismic damage prediction of $\mathrm{r} / \mathrm{c}$ buildings using artificial neural networks," Engineering Structures, vol. 165, pp. 120141, 2018.

[16] N. Wang, W. Cheng, M. Zhao, Q. Liu, and J. Wang, "Identification of the debris flow process types within catchments of Beijing mountainous area," Water, vol. 11, no. 4, p. 638, 2019.

[17] S. Park and J. Kim, "Landslide susceptibility mapping based on random forest and boosted regression tree models, and a comparison of their performance," Applied Sciences, vol. 9, no. 5, p. 942, 2019.

[18] H. Jia, J. Lin, and J. Liu, "An earthquake fatalities assessment method based on feature importance with deep learning and random forest models," Sustainability, vol. 11, no. 10, p. 2727, 2019.

[19] B. H. Menze, B. M. Kelm, R. Masuch et al., "A comparison of random forest and its Gini importance with standard chemometric methods for the feature selection and classification of spectral data," BMC Bioinformatics, vol. 10, pp. 1-16, 2009.

[20] D. P. Solomatine and D. L. Shrestha, "Adaboost.RT: a boosting algorithm for regression problems," in Proceedings 2004 IEEE International Joint Conference, Budapest, Hungary, July 2004.

[21] Code of China, "Chinese specification of seismic design for highway engineering (JTG B02-2013)," Code of China, Beijing, China, 2013.

[22] Code of China, "Chinese seismic intensity scale (GBT 177422008)," Code of China, Beijing, China, 2008.
[23] L. Chen, Report on the Highways' Damage in the Wenchuan Earthquake, China Communications Press, Beijing, China, 2012.

[24] Code of China, "Code for design of urban road engineering (CJJ 37-2012)," Code of China, Beijing, China, 2012.

[25] Code of China, "Chinese code for design of highway subgrades (JTG D30-2015)," Code of China, Beijing, China, 2015.

[26] D.-s. Ling, Y. Zhao, B. Huang, F. Zhang, and Y. Zhou, "Analysis of dynamic stress path in inhomogenous subgrade under moving aircraft load," Soil Dynamics and Earthquake Engineering, vol. 111, no. March 2017, pp. 65-76, 2018.

[27] I. Chowdhury, R. Tarafdar, A. Ghosh, and S. P. Dasgupta, "Seismic response of rectangular liquid retaining structures resting on ground considering coupled soil-structure interaction," Bulletin of Earthquake Engineering, vol. 15, no. 9, pp. 3695-3726, 2017.

[28] A. Imtiaz, V. Perron, F. Hollender et al., "Wavefield characteristics and spatial incoherency: a comparative study from argostoli rock-and soil- site dense seismic arrays," Bulletin of the Seismological Society of America, vol. 108, no. 5A, pp. 2839-2853, 2018.

[29] D. L. Shrestha and D. P. Solomatine, "Experiments with AdaBoost.RT, an improved boosting scheme for regression," Neural Computation, vol. 18, no. 7, pp. 1678-1710, 2006.

[30] China Earthquake Administration, "Classification of earthquake damage to lifeline engineering GB/T 24336-2009," China Standard Press, Beijing, China, 2009.

[31] Standardization Administration and State Administration for Market Regulation, "The Chinese seismic intensity scale GB/T 17742-2008," China Standard Press, Beijing, China, 2008.

[32] Ministry of Housing and Urban-Rural Development of the People's Repulic of China, "Code for design of urban road engineering CJJ 37-2012," China Architecture and Building Press, Beijing, China, 2016.

[33] Z. Safra and U. Segal, "Risk aversion in the small and in the large: calibration results for betweenness functionals," Journal of Risk and Uncertainty, vol. 38, no. 1, pp. 27-37, 2009.

[34] M. S. Asadi, R. P. Orense, M. B. Asadi, and M. J. Pender, "Post-liquefaction behavior of natural pumiceous sands," Soil Dynamics and Earthquake Engineering, vol. 118, pp. 65-74, 2019.

[35] S. Hatfield-Dodds, H. Schandl, P. D. Adams et al., "Australia is "free to choose" economic growth and falling environmental pressures," Nature, vol. 527, no. 7576, pp. 49-53, 2015. 